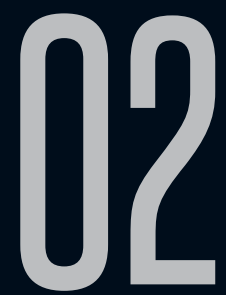

\title{
ENTREVISTA COM MÁRIO DE CARVALHO
}

Flavio Garcia (UERJ)

Luciana Morais da Silva (UERJ)

Recebido em 16 jun 2015. Flavio García (Queiroz de Melo) possui Doutorado em Aprovado em 21 out 2015. Letras - Literatura Portuguesa (PUC-Rio, 1999) e PósDoutorado em Ciência da Literatura - Poética (UFRJ, 2006-2008), em Letras - Estudos de Literatura (UFRGS, 2010-2012) e em Literatura de Língua Portuguesa (Universidade de Coimbra, 2015-2016, com PROCAD UERJ e BEX CAPES). É Professor Associado da UERJ, atuando nos Mestrado e Doutorado em Estudos de Literatura, nas especialidades em Literatura Portuguesa e em Teoria da Literatura e Literatura Comparada, e na Graduação em Letras. Coordena o Seminário Permanente de Estudos Literários da UERJ (SePEL.UERJ) desde 2001, co-coordena o Dialogarts Publicações desde 1996, coordena a Unidade de Desenvolvimento Tecnológico Laboratório Multidisciplinar de Semiótica (UDT LABSEM) desde 2014. Lidera o Grupo de Pesquisas "Nós do Insólito: vertentes da ficção, da teoria e da crítica (Diretório de Grupos CNPq, desde 2003) e coordena o Grupo de Trabalho "Vertentes do Insólito Ficcional (ANPOLL, 2011-2016). Divide a Editoria do Caderno Seminal, com Darcilia Simões, desde 1998, e da revista Abusões, com Kúlio França, desde 2015. Goza de Bolsa Prociência (UERJ-FAPERJ, desde 2014). Vem organizando Painéis, Encontros Regionais e Nacionais e Congressos Internacionais, bem como variadas publicações impressas ou digitais, em torno do 
Insólito Ficcional. É autor de Discursos fantásticos de Mia Couto: mergulhos em narrativas curtas e de média extensão em que se manifesta o insólito ficcional (2013). Orienta ou supervisiona pesquisas de Iniciação Científica, Mestrado, Doutorado e Pós-Doutorado, que se detêm no estudo do Insólito Ficcional, em culturas e literaturas de línguas portuguesa e galega. http://lattes.cnpq.br/4242057381476599

Luciana Morais da Silva possui Mestrado em Letras - Literatura Portuguesa (UERJ, 2012), tendo sido bolsista CAPES, e em Letras Vernáculas - Literaturas Portuguesa e Africanas (UFRJ, 2012), e é Doutoranda em Letras - Literatura Comparada (UERJ), com o projeto de pesquisa "Figurações da personagem e o universo insólito nos novos discursos fantásticos: narrativas curtas de Murilo Rubião, Mário de Carvalho e Mia Couto", desenvolvendo estágio na Universidade de Coimbra, com Bolsa de Doutorado Sanduíche no Exterior (FAPERJ). É autora de Novas Insólitas Veredas: leitura de A varanda do frangipani, de Mia Couto, pelas sendas do Fantástico (2013). http://lattes.cnpq.br/2847441618182578 


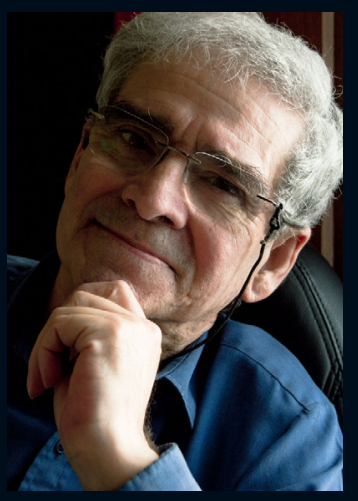

O ficcionista português Mário de Carvalho estreou, em 1981, com Contos da Sétima Esfera, espraiandose pelos discursos do metaempírico. Seguem-se Casos do Beco das Sardinheiras, de 1982, exemplo paradigmático dos novos discursos fantásticos, em que o Beco é um cenário de mundos possíveis, nos quais personagens, espaços, tempos e ações são configurados em subversão da ordem lógicoracional da arquitetura real-naturalista. Em 1982, publica $O$ Livro Grande de Tebas, Navio e Mariana, um romance cuja dinâmica narrativa se mantém nas bordas do insólito. Já no ano seguinte, 1983, retorna aos contos, com A Inaudita Guerra da Avenida Gago Coutinho, reunião de relatos igualmente insólitos, em que o escritor mescla muitas das técnicas antes utilizadas. Em 1984, vem a público Fabulário, conjunto de minirrelatos que ocupa um entrelugar, carecendo ainda de ser repensado com maior cuidado. Dois anos mais tarde, em 1986, saem Contos Soltos, espécie de coletânea de dispersos que andavam por aí aguardando serem compilados, dentre os quais há muito de insólito, sob qualquer dos aspectos que se possa abordar suas narrativas.

Em entrevista dada à Revista Ler, em 1996, ainda que não negasse sua incursão pelo fantástico, em especial com os seu Casos do Beco das Sardinheiras, Mário de Carvalho afirmou que, "uma vez as coisas feitas, há que passar adiante", admitindo que, "Em dado momento, havia o gosto pelo realismo mágico latino-americano", e "talvez isso [...] [o] tivesse levado a ir por aí". No "Epílogo" de Casos do Beco das Sardinheiras, a personagem-narrador-autor, em agastado diálogo com três de suas personagens Chico Estivador, Zeca da Carris e Zé Metade -, que vão à sua casa reclamar a continuidade da contação dos casos, sustém que não mais escreverá sobre 0 Beco, porque o vão "chamar um escritor menor", e diz estar "farto deste populismo-fantásticohumorístico-coiso...". 
O escritor, contudo, não conseguiu se afastar totalmente da literatura do insólito, tangenciando-a seja pela veia da carnavalização, da metaficção historiográfica ou recorrendo as estratégias de construção próprias as vertentes da narrativa fantástica, especialmente em suas manifestações a partir do início do Século XX. Quatrocentos Mil Sestércios seguido de O Conde Jano (1991), Contos Vagabundos (2000), A arte de morrer longe (2010), O Homem do Turbante Verde (2011) e A Liberdade de Pátio (2013) são volumes em que o autor retoma, de diferentes maneiras, com sutileza, dissimulação, ou não, os passos iniciais que dera pela ficção do fantástico contemporâneo. Naquela entrevista de 1996, Mário de Carvalho dissera que é "muito pronto para as facilidades em quase tudo, excepto na literatura", e tinha razão, pois não Ihe tem sido fácil escapar dos discursos da ficção do insólito, a que tem voltado inevitavelmente.

Meu caro escritor - fazendo eco de suas palavras em livro recente (Quem disser o contrário é porque tem razão - Letras sem tretas: guia prático de escrita de ficção, 2014), refiro-me a si como escritor, observando-o na especificidade de ser ficcionista -, nossa conversa poderia começar entorno de reflexões acerca de uma entrevista que Mário de Carvalho deu à Revista Ler, em 1996, e das falas de sua personagem-narradorautor no "Epílogo" dos Casos do Beco das Sardinheiras. Essa personagem, espécie de porta-voz da poética de seu criador - síntese de criador e criatura -, referindo aos relatos que estaria a dar por encerrados, e cujas personagens the cobram continuidade, diz-se "farto deste populismo-fantástico-humorístico-coiso...", a sustentar sua decisão de não mais escrever aqueles "casos", porque, se continuar a fazê-lo, o vão "chamar um escritor menor". 
P.: O Mário de Carvalho acha que a literatura fantástica encontrase no universo que a crítica delimita como literatura menor?

R.: Não, não acho. Aliás, teríamos que nos entender sobre o que é "a crítica". A crítica precisa de muita vigilância, para não andar ao sabor das modas nem à banca de gurus. Todos temos na ideia o papel pernicioso que coube ao pedantismo dum SainteBeuve no século XIX, em França. Há outros exemplos, e em Portugal também. Dificilmente um autor de colunas de jornal nos conseguiria convencer da "menoridade" de um Henry James em "The Turn of The Screw", de Stevenson em Dr. Jeckyl e Mister Hide ou de Bradbury em Martian Chronicles. Também o distinguir entre literaturas maior e menor nos pode levar a irritantes aporias. E para complicar mais ainda as coisas, pode aparecer a figura do "grande escritor menor".

P.: Para si, o discurso fantástico seria escapismo fácil, "populismofantástico-humorístico-coiso..."?

R.: Essa minha (aliás, jocosa) alusão não pode ser desligada do contexto da época. Estávamos em 1981. Pesavam ainda sobre a literatura portuguesa os fantasmas do noveau roman e da especulação estruturalista. A literatura queria-se apessoada, sisuda, pensativa, cerebral, maçadora e... estéril. As categorias da narrativa tinham sido colocadas entre parênteses, desvalorizava-se a imaginação e mandava-se o talento às malvas. Certas incapacidades (a incapacidade de conceber uma história com princípio, meio e fim, ou de desenhar uma personagem credível, por exemplo) eram consideradas, não como uma limitação de escritores - esses sim, menores - mas 
como uma opção estética de profunda implicação. Todas as épocas transportam as suas ilusões e mistificações, e esta foi, porventura, pasto de algum charlatanismo travestido de proposta literária.

P.: Havia, então, na fala daquela sua personagem-narrador-autor dos Casos do Beco... um teor jocoso, uma certa ironia?

R.: Mas todo o Beco das Sardinheiras está repassado de sentido lúdico. Ecoam nele as vozes dos bairros populares, os ditos, os trejeitos de uma certa maneira de estar muito lisboeta. E também uma capacidade - muito lusitana - de adaptação a novas realidades. Todos os eventos inusitados que acontecem nos microcosmos do Beco acabam por ser recuperados e absorvidos - com bonomia - pela população. O íncipit de todos os contos "uma ocasião", o lema "é preciso não confundir Género Humano com Manuel Germano" que aliás se tornou célebre, certo léxico "escanifobético", trazem essa marca risonha. Um crítico célebre na altura (também pelas más razões), João Gaspar Simões, atirou-se ao livro como gato a bofe. Era o pobre homem completamente destituído de sentido de humor. Mas detectou, quand-même um traço que está presente no Beco e merece ser salientado: a traça da tradição vicentina. Há aqui, de facto, ainda, a ressonância de Gil Vicente.

P.: Escrever literatura fantástica é seguir pelo caminho do populismo?

R.: Não necessariamente. Tanto como a literatura filosófica, a "de afectos", a sentimental, a de ficção científica e a de qualquer género. O populismo (ou o popularuchismo, como eu às vezes 
Ihe chamo) não poupa nenhum género. Há por aí obras que se reclamam do fantástico e são intragáveis. Mas pode passar por ele a grandeza e elevação literárias: estou a pensar em Jorge Luis Borges, Gabriel Garcia Marquez ou Cortázar.

P.: O discurso fantástico é ou precisa ser humorístico?

R.: E o discurso amoroso? Claro que não "precisa". Aliás, nestas matérias devemos ser cautelosos com a assertividade. Mas não deixa de ser interessante como o discurso humorístico se imbrica em narrativas maiores como A Guerra das Salamandras, A Fábrica do Absoluto (Čapek) ou Os Marcianos Divertem-se (Martians Go Home) de Fredric Brown.

P.: Todavia, suas narrativas em que o discurso fantástico, em sua vertente contemporânea, mais se deixa notar, são relatos nos quais o humor, muitas vezes corrosivo, aflora. Pode-se até sugerir que, no plano da história desses textos, o escritor está a fazer críticas ao sistema social, político, religioso etc. Como você comentaria, sob uma perspectiva de seleção dos protocolos ficcionais por parte do escritor, essa relação entre o fantástico e o humor?

R.: A crítica, belíssimo vocábulo, carregado de sentido, é uma das grandes conquistas do mundo ocidental e representa, ela própria, um avanço civilizacional, um exercício de liberdade e de uma atitude comportamental superior, que é a da interrogação e a dúvida. E quanto mais solenes e arreigadas são as instituições, mais elas pedem que sobre elas se exerça o crivo crítico, a desmistificação, o apontamento do irrisório e do ridículo. Eça de Queirós disse algures, nas Farpas, creio, 
que basta passar sete vezes uma gargalhada em volta duma instituição para que ela desabe com fragor. Bom, talvez Eça não tivesse inteira razão, mas é sempre saudável que a autoridade perceba que o riso está em cada esquina.

P.: Em sua opinião, o fantástico seria uma "coisa", nesse sentido genérico e impessoal, disforme, que atribui ao que se chama, em geral, de "coisa"?

R.: "Coisa" não tem que ser usada num sentido pejorativo. Corresponde à velha res que os romanos utilizavam a torto e a direito. "Coiso", no masculino, corresponde mais, na linguagem lisboeta (além de outras acepções que não vêm ao caso...), a uma hesitação, uma indeterminação.

P.: Logo, pode-se inferir, daquela fala de sua personagemnarrador-autor dos Casos do Beco..., uma certa consciência autoral - no sentido do autor-modelo de Umberto Eco sobre os protocolos da ficção fantástica, em relação à qual, independentemente da seleção vocabular - hesitação, para Todorov; incerteza, para Irène Bessière; ambiguidade, para Filipe Furtado -, toda a tradição teórica, crítica ou historiográfica, aponta como marca, traço distintivo, a indeterminação inquietante?

R.: Eu sei muito pouco. O que me consola é que sobre estas coisas, de uma forma geral, se sabe quase nada. A literatura é uma forma artística, pulsando com e contra o seu tempo. Os conceitos têm de acompanhar essa plasticidade, complexidade e fluidez. Naquela minha humilde expressão em Casos do Beco das Sardinheiras, eu quis deixar em aberto uma infinidade de 
possibilidades. Nestas matérias, sempre que alguém aparece a papaguear uma terminologia de conceitos rígidos, aprisionados em chaveta (ou power point) podemos dizer, quase de certeza, que estamos perante um camelô de feira.

P.: E o Mário de Carvalho incursionou pela ficção fantástica ou não?

R.: Uma das razões da minha "incursão" pelo fantástico (o vocábulo "incursão" foi bem escolhido) foi a sensação (porventura equivocada) de que, naquela altura, em Portugal, ninguém estava a escrever narrativas fantásticas, entendidas como aquelas em que a irrupção de um facto anómalo (não dependente das leis da natureza comuns e vigentes) vem perturbar uma normalidade estabelecida. E essa desertificação representava como que um convite a uma transgressão quase provocatória.

P.: A sua incursão pelo fantástico teve a literatura latinoamerica por referência ou inspiração?

R.: Sem dúvida que Borges e García Márquez (conhecidos em Portugal em meados dos anos sessenta do século passado) tiveram influência nas minhas coisas (cá está!), em especial em $\mathrm{O}$ Livro Grande de Tebas... Mas há também o reflexo de leituras de ficção científica, de Fredric Brown, por exemplo, esobretudo do grande Ray Bradbury. Também do checo Karel Čapek, do catalão Pere Calders ou dos ingleses James Hilton (Xangri-lá) e H.G. Wells. E, claro, do portentoso Kafka. E sem esquecer o longínquo Hoffmann, a gentil Mary Shelley e o atribulado Edgar Poe, como ressonâncias que se foram sempre fazendo sentir. 
P.: Em sua opinião de leitor crítico, bem próximo do leitormodelo equiano, que reconhece as regras do jogo ficcional, e admitindo-se que sua sensação, naquela época, houvesse sido de fato equivocada, que outros escritores portugueses também teriam incursionado pela ficção fantástica?

R.: Luísa Costa Gomes, com os Treze Contos de Sobressalto, Lídia Jorge com O Dia dos Prodígios e João de Melo com O Meu Mundo não é deste Reino.

P.: Tendo em conta a produção ficcional contemporânea, seja literária, seja cinematográfica - baseada ou não em narrativas literárias -, você diria, nos dias de hoje, como insinuou em 1996, que o discurso fantástico estivesse ultrapassado?

R.: "Ultrapassagem" é linguagem automobilística. Não há disso em literatura e em arte. Poderá haver géneros (como autores...) mais ou menos praticados, mais ou menos obnubilados, em tal ou tal época. Mas todas as obras de todos os tempos continuam vivas e a agir, num tecido sempre renovado como a tapeçaria de Penélope. Também pode acontecer que haja momentos de saturação. Isso provavelmente ocorreu com a literatura dita gótica. Deu a impressão em dada altura que tudo já estava inventado nesse terreno, e os lugares tradicionais (lugarescomuns) tornaram-se repetitivos e cansativos. Aquele ressurgir de ambientes "célticos", por exemplo, veio a ser insuportável. O Vampirismo tornou-se previsível e enfadonho. E o Senhor Dos Anéis apela em excesso à paciência dum leitor experimentado.

Também pode acontecer que um escritor prefira (e tenha forças para) não estar confinado a este ou àquele trilho, ou género. Há 
escritores andarilhos que preferem variar de paisagem...

Mas, já agora deixe-me recordar uma situação pessoal. Li O Conde Drácula de Bram Stocker na noite em que os primeiros homens chegaram à lua. Procurei acompanhar o evento pela televisão e ia lendo enquanto aguardava que as notícias fossem aparecendo no écran. O televisor encontrava-se na casa de jantar e eu sentava-me a uma grande mesa. De repente, um lápis que estava equilibrado caíu com estrondo. Foi um baque, um susto tremendo, coincidindo com a altura em que o protagonista, durante a fuga, é assediado por um grupo de mulheres vampiras. Tive mesmo medo e já não era nenhuma criança.

P.: Mário considera pertinente, mesmo de depois dos Casos do Beco..., que se façam leituras de outras de suas narrativas como próximas - senão que, mesmo, às vezes, centrais - ao fantástico?

R.: Eu não tenho nada que considerar "pertinente". Sou apenas um autor. Os meus livros são lidos por cada leitor de acordo com a sua própria vivência, enciclopédia pessoal e horizontes referenciais. Em O Livro Grande de Tebas... e Contos da Sétima Esfera parece-me perfeitamente legítimo classificar essas narrativas como da ordem do fantástico e, em alguns casos, mesmo, do maravilhoso.

P.: Os contos de A inaudita guerra da Avenida Gago Coutinho e muitas narrativas de Contos vagabundos não se aproximam desse mesmo matiz? Ou, ainda, você não retornou, atualizando técnicas narrativas, às mesmas sendas do discurso fantástico, com $\mathrm{A}$ arte de morrer longe, por exemplo? 
R.: Sim, e também os Contos da Sétima Esfera, para não falar dessa obra sonâmbula chamada O Livro Grande de Tebas, Navio e Mariana. Agora, não creio que A Arte de Morrer Longe faça intervir o absurdo, ou o insólito nem que paire por lá essa "estranheza inquietante" de que falava, ao que creio, Sigmund Freud. Eu classifiquei A Arte de Morrer Longe entre os cronovelemas, ou seja, aquele género literário, de actualidade, em que se misturam e confundem a crónica, a novela, o poema (o cinema), o humor e o ludismo estilístico e em que o autor não deixa de participar.

P.: Hoje, analisando a sua trajetória como ficcionista, bem como a produção ficcional em geral, você diria que o recurso ao fantástico é, está sendo, foi uma escolha consciente ou não?

R.: Uma escritora portuguesa minha amiga, Luísa Costa Gomes, usou uma vez uma expressão feliz que eu já utilizei, até, numa epígrafe: "era uma vez uma história que tinha uma grande vontade de ser contada". Isto diz tudo. As histórias oferecemse e o autor (sempre com o seu cúmplice leitor) desvenda-as.

P.: Se, em seu "manual", Mário de Carvalho houvesse dedicado algum comentário em relação a um aprendiz de escritor que pensasse em trilhar os caminhos da ficção fantástica, enveredando pelos discursos do metaempírico, o que escreveria para esse iniciando?

R.: O mesmo conselho que daria a qualquer aprendiz de escritor, e que já vem do fundo dos tempos: esto brevis. Sê breve. E, seja qual for o género escolhido, não deixe de frequentar os grandes mestres, António Vieira, Camilo, Machado de Assis, Eça de Queirós. Ajudam-nos a ir mais longe. 
P.: Dentre os nomes que você destacou, dois deles, em especial, são baluartes das literaturas de seus países - Eça de Queirós, para Portugal, e Machado de Assis, para o Brasil -, ambos bastante comprometidos com o sistema semionarrativoliterário real-naturalista, ligados a tendências poéticas de mimeses referencial bastante condicionada à lógica racionalista aristotélica - no caso de Eça, sua militância na Geração de 70 é um dado complicador de maior dimensão. Contudo, a crítica acadêmica tem se detido a ler algumas de suas obras como representantes da ficção do insólito - fantásticas, lato sensu. Retomando a sua qualidade de leitor-modelo, que comentários poderia tecer acerca desse fenômeno?

R.: Eu protesto: Eça e Machado de Assis não são apenas grandes autores dos seus países e das suas línguas. São grandes autores da Literatura Universal. Como é que esses grandes autores podem deixar de estarem presentes, de uma forma ou de outra, nas nossas coisas (cá está, outra vez!). Nós não respondemos apenas perante os leitores e confrades: respondemos perante toda uma literatura. Pessoalmente desconfio dos escritores, pratiquem eles qualquer dos géneros, que não reagem perante os grandes autoresfundadores. Que mais não seja para os repudiarem - com conhecimento de causa. Eu lembro-me sempre da magnífica erudição literária - e sem preconceitos - dum Jorge Luis Borges, outro autor imprescindível.

É que os livros são feitos de palavras, organizadas de certa maneira. Uma forma banal ou descuidada não seduz, não convence, não muda o mundo, nem o leitor. Muitos dos 
livros apresentados no comércio como page turners (passe o anglicismo) e que tanto entusiasmam o jornalismo menor, não resistem ao célebre teste da página $99 . .$.

P.: O leitor brasileiro não tem, facilmente, acesso à totalidade de sua obra, mas teve, a um custo bastante viável, consideradas as condições socioeconômicas do país, a facilidade de ler, reunidas em um único volume, muitas narrativas originariamente publicadas em três diferentes livros, que espelham a diversidade temática e de recursos estéticos e estilísticos que marcam seu percurso autoral. Nesse conjunto, por exemplo, encontra-se, na íntegra, Casos do Beco das Sardinheiras, de que nesta entrevista muito se falou. Como o próprio autor, Mário de Carvalho, avaliaria essa publicação brasileira, não no que se refira à sua qualidade, mas no que tange ao seu conteúdo ficcional?

R.: Um grande poeta português, Alexandre O'Neill, referiu-se uma vez aos escritores que gostam de "lamber a cria", isto é que não deixam de se deslumbrar com o texto já publicado. Eu não sou esse tipo de autor. Uma vez uma obra publicada, vai à sua vida e faz-se ao mundo. Provavelmente nunca mais será relida pelo autor e poderá até ser esquecida. Tenho, aliás, muita relutância em ler os meus próprios escritos. Quanto à organização e arrumação dos textos envolve já questões editoriais que não me parece sejam inteiramente da competência do escritor. Estas coisas (outra vez!) costumam ser conversadas com o editor em termos de bom senso e interesse comum. Mas gosto de separar as águas. Não interfiro no trabalho dos outros e prefiro que não interfiram no meu. 
P.: Por fim, que recado nosso ficcionista quer deixar para os leitores de Abusões, em sua farta maioria investigadores da literatura do insólito, dos discursos do metaempírico, das narrativas, gótica, fantástica, feérica, onírica, enfim, não realista, descompromissada com a lógica racionalista aristotélica?

R.: Recomendaria para já um grande respeito por Aristóteles e pela sua Poética que, dois mil e quinhentos anos depois, nos tem ajudado a pensar a narrativa, na literatura, no teatro e no cinema. Em segundo lugar, convidaria à desconfiança em relação à extravagância, adoptando a noção de que mesmo dentro da história mais absurda, o leitor tem que ser levado a acreditar, prestando-se à tal "voluntária e momentânea suspensão da descrença" em que falava Coleridge. Finalmente, atrever-me-ia a um apelo para a necessidade de muitas e variadas leituras (não necessariamente de obras-primas) que contribuam para evitar que se repita o que outros já disseram e que se invente o que já foi inventado.

Edição brasileira da obra de Mário de Carvalho

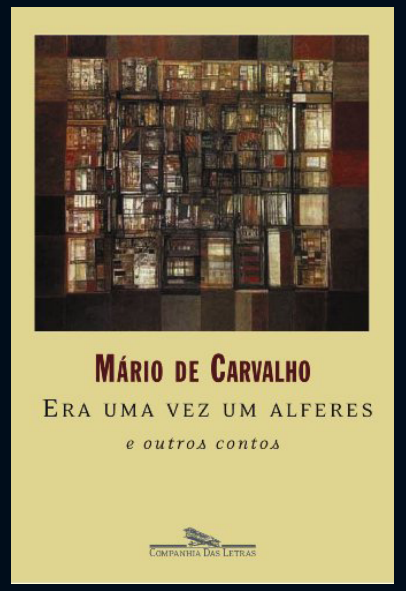

Era uma vez um alferes Companhia das Letras, 2008

\section{2 páginas}

Este livro reúne três obras de Mário de Carvalho:

- Casos do Beco das Sardinheiras (contos), 1982;

- $\quad$ Os alferes (contos), 1989;

- Quatrocentos mil sestércios seguido de O Conde Jano (novelas), 1991. 